\title{
Is Social Capital Motivated by Self-interest Only? A Case Study on a Well-developed U.S. Rural Community
}

\author{
Zhenyu Zhang ${ }^{1, *}$, Gary Lynne ${ }^{2}$ \\ ${ }^{1}$ College of Economics \& Management, Shanghai Ocean University, China \\ ${ }^{2}$ Department of Agricultural Economics, University of Nebraska-Lincoln, USA
}

Copyright $\mathrm{O} 2016$ by authors, all rights reserved. Authors agree that this article remains permanently open access under the terms of the Creative Commons Attribution License 4.0 International License

\begin{abstract}
The paper examines individual motivation about social capital, measured by willingness to accept of compensation to leave individually valued social relations behind in moving from an ideal-type mid-western rural community, referred to "Nirvana." The Heckman two steps method is applied to analyze a survey conducted in Nirvana. In Step1, 665 observations are used to run a Probit estimate on the individual decision to move. In Step2, 438 observations are used to perform a Semi-log OLS estimate of social capital value. The empirical analysis suggests that social capital investment is driven by the dual motivation represented in an egoistic based self-interest and an empathy-sympathy based other-interest, both of which are jointly pursued within the own-interest. This finding implies that community development strategies need to determine the nature of orientation when internalizing the own-interest of individuals in the community in question. This paper provides direct empirical evidence to support that both self-interest and other-interest motivate the investment of social capital in a well-developed rural community. It also helps understanding why some rural communities achieve a higher state of economic development and community vitality than others. To answer question about what level of self-interest conditioned by the shared other interest works best, will require further testing in various communities, other than just one case study.
\end{abstract}

Keywords Social Capital, Rural Development, Joint Interest, Probit Model, Semi-log OLS Estimation

JEL Classification: R22

\section{Introduction}

Historically, there have been two broad intellectual streams in explaining social action. One, following the work of most sociologists, sees the actor as a socialized individual, with actions governed by social norms, perhaps even willing to sacrifice self-interest to achieve shared other-interest in the greater good. The other, following on the work of most economists, sees the actor having goals independently arrived at, and acting wholly on self-interest. In the latter conception, social capital has no role itself, which seems contrary to experience. During the past-20 years, researchers have found empirical evidences that social capital explains the difference in economic growth rate[1], regional difference in economic success[2], and difference in economic outcomes [3-4]. Based on a set of survey, Schmid and Robison [5] tests for the existence of social capital and explores its impact on productivity and utility. Reference [5] concludes that social capital is a productive asset, which does affect transaction cost in farmland leasing [6], and the identity of the parties to a market transaction does affect the price. While Onyx and Bullen [7], Cordes et al [8], and Rupasingha, et al[9] have actually measured the social capital in term of attachment value to one's community, and Rupasingha et al. [9] also identified ethnic homogeneity, attachment to place as potential determinants of production of social capital at the U.S. county level. Teilmann [10] applies an index method to measure the accumulation of social capital in rural development, has tested the connections between motivation of pursing rural development and degree of social capital in Denmark, and suggests that higher level of motivation leads to increased social capital. Pochebut [11] uses a descriptive model to demonstrate four different strategies of managing social capital, and suggests that the allocation of strategies is based on two criteria: pro-social or pro-self orientation. They argue that individuals should carefully choose the strategy as an instrument for achieving social welfare, which suggests that motivation of accumulation social capital is from maximizing its own welfare, such as enhancing production efficiency [12-15].

Intriguingly, little research has been done on exploring by empirical test what actually motivates individuals to invest in and consume the product emerging from social capital. In this paper we'll examine the motivation behind individuals' choice to invest in social capital using empirical study. 
Generally, many previous studies suggest either that self-interest itself [16-17] or a self-interest driven reciprocity [18] triggers an individual's willingness to invest in social capital. On the other side, reference [19-21] suggest that social capital is motivated by sympathy, and in some sense social capital is sympathy, which seems to put emphasis on a shared other-interest, and is consistent with the meaning of social capital in sociology, albeit this is an argument being made by these economists.

A number of researchers from both traditions (economics and sociology) have recognized these opposite perspectives, and have attempted to impart some of the insights and orientations from the one to the other. The examples of studies [22-25] argue that mono-motive theories fail to explain individual behavior, and people go beyond benefit-seeking-based self- interest. Bowles and Gintis [26] use game theory and experimental economics to examine the role of social capital, and suggest that individual motivations supporting community governance are the integration of self-interested preferences and unconditional altruism towards fellow community members. We can also make sense of the Putnam [27] contention that social capital is on the decline by a shift toward the more individualistic path and away from the shared other-interest path, a discernible trend in the U.S. in the last few decades.

Most sociologists believe that rational actor theory is inadequate for sociological assessment of economic structures and process, because actors not only are driven by self-motives, but also portray a mixture of motives in their decisions [28]. The challenge to economic sociology is to find a better way to represent both under- and over-socialized version of human behavior [29]. The same challenge is faced in behavioral economics, as McCloskey [30] characterizes it, the focus of traditional economics only on one virtue, maximizing utility version of the person, and the real possibility for conditioned self-interest is left out. Solomon [31] argues that Smith's moral sentiments are really sympathies, and there would be no motivation for ethics without compassion (sympathy). These ethics, driven by shared sympathies arising from projection through empathizing with others, in turn, are essential to achieving own interest, including self-interest and shared other (sympathetic, ethical)-interest. The integrated theories from evolutionary psychology, neuroscience and socioeconomics are used in several studies [32-35] to demonstrate and recognize the existence of dual motives behind the formulation for reciprocity and exchange behavior of humans.

Social science literature generally has not adequately explained why social capital is produced, invested in, and/or consumed in the first place. And little has been said about what role it may play in guiding individual behavior and community development, at least not with empirical evidence. The fundamental questions yet to be answered include: Does social capital exist? Whether it exists only because individuals expect it to further their self-interest? Will individual share a common other-interest, which in turn, results in tempering self-interest pursuit? Scholars attracted to the concept of social capital seem to implicitly see the duality in human behavior, seeing there could an important role of social capital stocks in reducing the incidences of other social problems, reflecting other-interest, having an impact on economic development, and reflecting the individualistic self-interest. In this study, we have solid empirical evidence to support the $\mathrm{co}^{-}$existence of self-interest and other-interest represented in survey based experiments, and recognizes the dual motives, emerging as the simultaneous pursuit of both interests.

\section{Method and Data}

The bulk of the social capital and development literature provides little direct empirical evidence to support the concept of either self-interest or other-interest motivates the investment of social capital, none of which focusing on the possibility these two interests are jointly pursued. We focus herein on joint motives in a case study of "Nirvana" (so named in an earlier paper from this study, Cordes et al [8]). Nirvana is known to be a community wherein individuals experience a relatively high level of community and economic vitality, arguably higher than many other rural areas in USA. We hypothesize that the observed viability is likely due to a sympathy influenced emergence of a conditioned self-interest, the degree to which reveals a major reason for the emergence and existence of Nirvana-type places.

The survey was conducted in 2000, and collected 1012 residents' perspectives, including detailed measurements on a standard psychology scale about the extent to which self-interest is a driver in their economic choices. The fact that 68-percent of those surveyed did respond (survey was sent to everyone having a Nirvana zip code), which is much higher than the "usual" survey response rates of 20-30-percent, and such high response alone indicates something is different in this community. Even the survey response rate suggests a larger sense of shared other-interest at work and being in sympathy with one another, as 68-percent of residents in this community were willing to help a research team better understand the driving forces in their community.

As described in detail in Cordes et al. [8] contingent valuation methodology was applied to obtain a quantitative measure of the dollar value of social capital. The key question (Q16) used to form the dependent variable, which gives dollar value relating to consuming social capital good $\mathrm{q}$ (implicitly investing in the social capital to produce it). The respondent was told that the new job would be about the same in terms of job satisfaction; they currently know no one in the new community; which is similar on other fronts, except that close friends, business associates, etc.. And the new place is also at some distance; limiting the opportunities for only a few to no visits back to Nirvana per year. As a result, the respondent would lose all their current social 
capital after moving. As Sally [36] argues, being in sympathy with someone else generally requires proximity-with. The respondents answered two questions pertaining to form this dependent variable:

1) Would you and your household consider leaving Nirvana for additional income?

No, I cannot imagine my household leaving no matter how much money was offered.

Yes, for enough income, we would move.

2) If yes, how much additional annual income would it take to get your household to move?

In effect, we measure the value of social capital good foregone as an opportunity cost, how much would be sacrificed in social connections by leaving. Also, the idea is: if individuals are purely self-interested as traditional economics suggests, everyone would answer "yes." All respondents in the survey would choose to leave the community for even modest amounts of additional income, and suggesting individuals are purely monetary driven. So the empathy-sympathy represented in social capital does not motivate staying in its own right. What we actually observe in the case of Nirvana is inconsistent with such speculation, and is especially demonstrated by a substantive number of residents unwillingness to even consider moving from Nirvana at all, i.e. 38-percent of the respondents said "no" (with 68-percent of the population responding, we feel quite confident to claim the representativeness of whole population in the area). For the 62-percent answering "yes," social capital is more fundamentally an economic good, albeit as we will see in the empirical results, there is still a varying degree of shared other-interest conditioning the dollar value.

Overall, these questions give dependent variables of the $(0$, $1),(0, X)$ and continuous $X$-type, the latter for those who said "yes" and gave a dollar estimate. Because only those who answered "yes" have given the dollar measure on social capital, which creates a potential sample bias problem, a sample selection model proposed by Heckman [37] was applied, using Shazam student version 10.0

Step 1 is the decision stage for individuals to decide whether the social capital good can be monetized, where the dependent variable $\left(\mathrm{y}_{1}\right)$ is binary choice. 1 corresponds to the answer "Yes", considering the possibility of leave, and 0 is "No," not considering leave even with a promising financial opportunity. For this decision, the independent variables include the degree of selfishness $\left(\mathrm{X}_{1}\right)$; how self-interest is conditioned by others $\left(\mathrm{X}_{2)}\right.$, implicitly by the shared other-interest); how self-interest is conditioned by the perceived degree of control over one's own decision $\left(\mathrm{X}_{3}\right)$; household net annual income after taxes $\left(\mathrm{X}_{4}\right)$; self-interest in a job $\left(\mathrm{X}_{5}\right)$; other-interest in a job $\left(\mathrm{X}_{6}\right)$, with particular reference to coworkers); and an interaction term between the last two terms $\left(\mathrm{X}_{5} * \mathrm{X}_{6}\right)$. The overall result is a representation of the own-interest in social capital which represents the internally integrated and balanced self- and other-interest.

Step 2 is the dollar valuation stage for choosing leave. The dependent variable $\left(\mathrm{y}_{2}\right)$ is the additional annual income required by respondents who are willing to monetize the social capital through willingness to move for more money, represented in the natural logarithm of the dollar value. The independent variables include all variables except the degree of selfishness $\left(\mathrm{x}_{1}\right)$ defined in step1, plus the IMR (Inverse Mill's Ratio, correcting the sample selection bias caused by the correlation between the two steps).

The questionnaire draws heavily on the meta-economic approach. The possibility that individuals may pursue mainly for measures of selfishness, while those with wiliness to be influenced by others, perhaps evolves a shared other-interest in making this community better. The meta-economic approach also elevates the matter of both self-control and external control by others to a higher plane. Lester [38] suggests that it is human nature to continually wrest away from the inherent control asserted by others, and always seeking autonomy, expressed as being complementary to the pursuit of self-interest. So, wanting more individual control and self-interest tends to work together.

On the other hand, the influence of others tends to work counter to the pursuit of the self-interest. If influence of others is found a driver, this simply indicates the individual tends to condition the pursuit of self-interest on the other-interest, after answering the question "how would I wish to be treated if it were me in that situation?" With symbiosis in both interests inherent to the process and synergy a real possibility as argued earlier.

Due to the incomplete answers in the survey, 665 observations are used for the Step 1 analysis. Among 665 respondents, 438 individuals say 'yes' and are willing to sacrificing the social capital (connection) by leaving this community for extra money. And 227 individuals say 'no', as social capital is not something to them that can be converted into money. The level of money information from 438 individuals is used in Step 2 analysis.

The description of all variables is listed in Table1. The variable $\mathrm{X}_{1}$ used to measure the tendency toward pursuing the self-interest is the average of the reversed Q28 items, items ${ }^{1}$ like "Thinking of yourself first is no sin in this world today" and "Call it selfishness if you will, but in this world today we all have to look out for ourselves first", while the scales on the Q28 items are reverse coded before entry into the regression analysis. This is a commonly used for psychological scale, developed by Phares and Erskine [39].

The influence variable $X_{2}$ is $X_{1}$ multiplied by influence, drawn from the individual components of Q19, items like "My close friends/neighbors believe I should stay" measured on an extremely unlikely to extremely likely scale, multiplied by the respective components of Q20, items pertaining to whether the respondent placed an extremely low-extremely high value on "Views of friends/neighbors" resulting in an expectancy-valence variable, a proxy for the utility gained from being influenced by others.

1 All items are available at http://social .capital.unl.edu/nirvanaquest.pdf 
The control variable $X_{3}$ is computed as variable $X_{1}$ multiplied by control, regarding to Q27 ("Generally, having complete control over the decision to move is on the extremely important-extremely unimportant scale"), which was reversed in order to represent the extent to which the respondent believes others are not likely to control the decision. It was reversed because we wished to form and test for a variable that would potentially dampen self-interest. We would expect that if the individual perceived it was more unlikely that someone could control their decision to move, then they would be less likely to express their self-interest in moving. It is just like Angyal [40] did and consistent with Sally[41], that individuals are most always wanting more freedom to choose, so if they have it already, they don't have to, in this case, move away to obtain that freedom.

The variable $\mathrm{X}_{5}$ is the average of an expectancy-valence or proxy for utility; in this case the self-interest utility gained by the respondent in her/his work. The other-interest utility $\mathrm{X}_{6}$, gained from relationships at work.

Table 1. Variables description

\begin{tabular}{|c|c|c|}
\hline $\begin{array}{c}\text { Independent } \\
\text { Variable }\end{array}$ & Description & Remark \\
\hline $\mathrm{X}_{1}$ & $\begin{array}{c}\text { Tendency toward pursuing the } \\
\text { self-interest }\end{array}$ & Self-interest \\
\hline $\mathrm{X}_{2}$ & $\begin{array}{c}\text { Interaction between variable } \mathrm{X}_{1} \\
\text { and influence by others (relative, } \\
\text { friends) }\end{array}$ & Other interest \\
\hline $\mathrm{X}_{3}$ & $\begin{array}{c}\text { Interaction between variable } \mathrm{X}_{1} \text { and } \\
\text { unlikely controlled by others' } \\
\text { decision }\end{array}$ & Other- interest \\
\hline $\mathrm{X}_{4}$ & Income & Self-interest \\
\hline $\mathrm{X}_{5}$ & Expected utility gained from work & Self-interest \\
\hline $\mathrm{X}_{6}$ & $\begin{array}{r}\text { Expected utility gained from } \\
\text { relationship at work }\end{array}$ & Other-interest \\
\hline
\end{tabular}

\section{Results}

The Probit model is used for the decision analysis in Step 1 , whether or not consider moving, and Table 2 present the results.

Table 2. Probit estimates on the individual decision to move

\begin{tabular}{|c|c|c|c|}
\hline $\begin{array}{c}\text { Independent } \\
\text { Variables }\end{array}$ & $\begin{array}{c}\text { Estimated } \\
\text { Coefficient }\end{array}$ & $\begin{array}{c}\text { Standard } \\
\text { Error }\end{array}$ & P-value \\
\hline $\mathrm{X}_{1}$ & 149.93 & 21.95 & $<0.0001^{* * *}$ \\
\hline $\mathrm{X}_{2}$ & -3.51 & 0.53 & $<0.0001^{* * *}$ \\
\hline $\mathrm{X}_{3}$ & -12.22 & 3.52 & $0.0005^{* * *}$ \\
\hline $\mathrm{X}_{4}$ & 0.000023 & 0.000019 & 0.24 \\
\hline $\mathrm{X}_{5}$ & 0.040 & 0.0096 & $<0.0001^{* * *}$ \\
\hline $\mathrm{X}_{6}$ & 0.023 & 0.010 & $0.026^{* *}$ \\
\hline $\mathrm{X}_{5} \mathrm{X}_{6}$ & -0.0012 & 0.0003 & $-<0.0001^{* * *}$ \\
\hline Constant & -0.59 & 0.21 & $0.005^{* * *}$ \\
\hline
\end{tabular}

$* * *, * *$, and $*$ indicates the statistical significance at $1 \% ; 5 \%$ and $10 \%$ respectively. Sample size is 665 .

Probit results show that all explanatory variables, except the income $\left(\mathrm{X}_{4}\right)$, are statistically significant for the decision step, while variables associated with selfishness $\left(X_{1}\right)$, self-interest related to the current job $\left(\mathrm{X}_{5}\right)$ and other-interest utility related to coworker relationship $\left(\mathrm{X}_{6}\right)$ have a significantly positive impact on people's decisions; and variables corresponding to self-interest conditioned on other-interest $\left(\mathrm{X}_{2}\right)$, by other control $\left(\mathrm{X}_{3}\right)$; and the interaction between self-interest and other-interest from work $\left(\mathrm{X}_{5} * \mathrm{X}_{6}\right)$ have a significantly negative impact on people's decision to leave.

The positive impact means that the individuals with high level of self-interest are more likely to leave the community for extra money. The negative impact means that the individuals condition their own interest by other-interest or other control are less likely to leave the community for another financial opportunity. Notice that the income $\left(\mathrm{X}_{4}\right)$ effect is statistically insignificant, suggesting the income essentially plays no role in the decision to stay or to leave, which provides even more support for our contention that something besides monetary considerations are at work in Nirvana in this first stage of decision.

The results in Table 2 are generally within the expectations of traditional economics, regarding to those factors that drive decision to give up social capital in Nirvana for more money: i) $X_{1}$, the more self(ish)-interested the individual, the more likely job is a major source to make a living in satisfying self-interest, and more likely they will choose leaving for more lucrative job opportunity; ii) $\mathrm{X}_{5}$, the more value individuals put on a job, the more likely they will choose leaving for a new job, that is, "the job" no matter where it is located has a high value in the self-interest sense; iii) $\mathrm{X}_{6}$, the more values collaborators at work, logically being able to have this same feature in a new job (the contingency describes how the job situation and working environment will be essentially the same, except the pay will be higher), the more likely to leave from easily building up new relationship at work with higher pay. What is really intriguing is the evidence found in this study supports the hypothesis that the empathy-sympathy based other-interest plays a substantive role as the self-interest does.

Three other-interests variables $\left(\mathrm{X}_{2}, \mathrm{X}_{3}, \mathrm{X}_{5} * \mathrm{X}_{6}\right)$ have a dampening effect on the individual's decision to leave Nirvana. This is to say, being in sympathy with shared norms and shared interests arising in connections with others tempers the prudence-only, "Max U" (as noted earlier, see McCloskey [38], for a similar argument) drive characterized on path $0 \mathrm{G}$. (iv) $\mathrm{X}_{2}$, the more consideration for others in the sense of empathizing and being in sympathy with them, the more likely tempering one's own decision, the less likely the individual will choose to leave; (v) $\mathrm{X}_{3}$, the less perceived control there is on the individual's own decision from others, the less likely the individual will choose leaving, and finally, (vi) $\mathrm{X}_{5} * \mathrm{X}_{6}$, the self-interest arising in the job itself is conditioned by the other-interest from work, suggesting that sharing more in the other-interests with co-workers from the current job, the less likely one is to leave for a new similar job. 
The negative sign on $\mathrm{X}_{5} * \mathrm{X}_{6}$ is because there is some kind of feedback and interaction between the two interests, which make this job work well for these individuals, and makes them reluctant to leave it. In terms of support for what might motivate consuming social capital going beyond both traditional economic and sociological renditions, the most substantive findings are from significant role of others in conditioning self-interest $\left(\mathrm{X}_{2}\right)$, and insignificant role of annual income $\left(\mathrm{X}_{4}\right)$. Another substantive finding is that self-interest remains an important driver, because motivation is not purely about social networks and being bound in a community. Both economics and sociology gain strength from integrating these two main ideas into one framework.

The Inverse Miller's Ratio (IMR) was created using Probit results from Step 1, capturing the correlation of decisions between Step 1 and Step 2. And IMR was used as one of the independent variables in Step 2 in order to correct for the sample selection bias problem. The coefficient of IMR is 0.98 ( $p$-value $=0.12$ ), suggesting the existence of selection bias problem is insignificant and not much gain has been achieved from using the Heckman two stage method to run the analysis. Therefore, Table 3 reports the semi-log OLS estimation without including IMR for correcting sample selection bias.

Table 3. Semi-log OLS estimates of social capital value

\begin{tabular}{|c|c|c|c|}
\hline $\begin{array}{c}\text { Independent } \\
\text { Variables }\end{array}$ & $\begin{array}{c}\text { Estimated } \\
\text { Coefficient }\end{array}$ & $\begin{array}{c}\text { Standard } \\
\text { Error }\end{array}$ & P-value \\
\hline $\mathrm{X}_{2}$ & 4.0 & 1.52 & $0.0044^{* * *}$ \\
\hline $\mathrm{X}_{3}$ & -9.67 & 7.12 & 0.91 \\
\hline $\mathrm{X}_{4}$ & 0.000017 & 0.0000056 & $0.0013^{* * *}$ \\
\hline $\mathrm{X}_{5}$ & 0.074 & 0.014 & $0.012^{* *}$ \\
\hline $\mathrm{X}_{6}$ & 0.080 & 0.013 & $0.0067^{* * *}$ \\
\hline $\mathrm{X}_{5} \mathrm{X}_{6}$ & -0.0025 & 0.00046 & 0.98 \\
\hline Constant & 5.13 & 0.82 & $0.00^{* * *}$ \\
\hline
\end{tabular}

***,**, and * indicates the statistical significance at $1 \% ; 5 \%$ and $10 \%$ respectively. Sample size is 438

The semi-log OLS results in Table 3 show that for those willing to monetize it, $\mathrm{X}_{2}{ }^{2}$ has a positive effect on the dollar value of social capital, which also supports the hypothesis. In Step 1, instead of presuming the consumer of social capital is a creature pursuing only self-interest or only other-interest, we see empathy-sympathy operating to create a shared other-interest conditioning on the self-interest. As argued earlier, standard economic theory was already challenged by the fact that 35- percent said "No". Apparently, there was shared other-interest at work, a result that probably would not have surprised most sociologists, who may have expected it to be even 100 percent. Yet, Step 2 analysis gives more credence to traditional economic versions of this story too, in some sense also challenging sociology based versions of the story, in that for the 65-percent who said "Yes". The

2 that the variable conditioning the self-interest due to the influence from significant others average required compensation was nearly $\$ 33$ thousand, suggesting the monetary value of social capital to those willing to monetize it is substantial in the community, where the typical income is around $\$ 25-35$ thousand. It would require a full doubling in income to leave their social capital behind. Also, as expected, control is no longer a force in the Step 2 decision. Once people visualizes actually moving and considers how much money to take, the individual has already disconnected the psychological and sociological sense from others, who might be perceived as controlling.

By explicitly introducing both other-interest and self-interest into the framework, we are now supporting both standard economic and sociology theory, and their approaches. Sociology would suggest a role for the social connections represented in social capital, and not everything can be monetized, as supported in the Step 1 analysis; some sense of unity with the community of interests is an important driver. As economics teaches, self-interest plays a substantive role in both steps. For those willing to put a dollar value on it, standard economic theory predicts that the value is higher for one who has more income, or put more value on a job, or on co-workers, although the magnitude of income effect is tiny. Meta-economics predicts that both money and community-wide connections represent important features, at least for communities, which are economically and socially viable as that represented in Nirvana.

\section{Conclusions}

As Robison and Flora [19] argue, much of human behavior does not appear to be motivated by selfish preference for increases in physical goods and services. Examples of such behavior include unwillingness to move from one's community for a significant pay increase, and attachment to things with little physical value. The social capital paradigm explains some of these nonmaterial-oriented behaviors by integrating behavioral concepts and assumptions from the fields of economics, psychology, and sociology.

This study supports this contention, albeit we need to keep in mind this community was chosen for study in the first place as it represents an ideal, Nirvana-like place. As noted, the results reported in this case study of Nirvana also provide a new prospective into traditional theories in both economics and sociology. Perhaps even more importantly, at least pragmatically if not theoretically, this study sheds new light on understanding why some rural communities achieve a higher state of economic development and community vitality than others, with implications for community development strategies, and perhaps policy. It makes little sense, for example, to focus only on job-creation (i.e. corresponding to the view of the economic person), or only on leadership skills for enhancing community networks (i.e. corresponding to the perspective of the social person). Also, 
the appropriate mix of these two thrusts depends on the nature of people of the community in question. Detailed profiles, using scales to characterize personality-types as well as other social (e.g. network) measures, are needed in order to customize policies and strategies that will work in a particular community. One size does not fit all.

Yet, this is just one case study. To answer the question about what level of the self-interest conditioned by the shared other-interest works best will require further testing in various communities representing the full-spectrum of development. If further testing supports focusing on moving to the ideal orientation found in these studies, we would then have a scientific basis for designing and implementing policies and programs to bring about the economically viable community development. This paper also points to the fertile ground in the overlap areas of economy and sociology, seeing the important role for both the self and the other interest in economic and social choice, and further testing this meta-economics approach.

\section{Acknowledgements}

The data used in this paper is drawn out of a larger study funded by a U. S. Department of Agriculture, National Research Initiative-Community Development grant, and which was conducted in a team effort by a group of economists and sociologists, led by Sam Cordes, including John Allen, Richard C. Bishop, Gary D. Lynne, Lindon J. Robison, Vernon D. Ryan and Ron Shaffer. This paper represents the views and perspectives of the authors, and any remaining problems and errors are attributable to the authors as well.

\section{REFERENCES}

[1] A. Rupasingha, J. S. Goetz and D. Freshwater. Social and institutional factors as determinants of economic growth: Evidence from the United States, Regional Science, Vol. 81, No.139-166, 2002.

[2] G. Torsvik. Social Capital and Economic Development: A Plea for the Mechanisms, Rationality and Society, Vol.12, 451-476, 2000.

[3] M. Woolcock. Place of Social Capital in Understanding Social and Economic Outcomes, Canadian Journal of Policy Research, Vol. 2, 11-I7, 2001.

[4] S. N. Durlauf and M. Fafchamps. Social Capital, Working Paper 10485, National Bureau of Economic Research, 2004.

[5] A. A. Schmid and J. L. Robison. Applications of Social Capital Theory, Journal of Agricultural and Applied Economics, Vol.27,59-66, 1995.

[6] K. Gwilliam. Farmland Leasing and Contract Choice in Michigan: The Influence of Social Distance. Ph.d. Thesis. Michigan State University, East Lansing, 1993.
[7] J. Onyx and P. Bullen. Measuring Social Capital in Five Communities, The Journal of Applied Behavioral Science, Vol.36, 23-42, 2000.

[8] S. Cordes, J. Allen, R. C. Bishop, G.D. Lynne, L.J. Robison, V.D. Ryan and R. Shaeffer. Social Capital, Attachment Value and Rural Development: A Conceptual Framework and Application of Contingent Valuation, American Journal of Agricultural Economics, Vol. 85, 1201-1207, 2003.

[9] A. Rupasingha, J. S. Goetz and D. Freshwater. The Production of Social Capital in US Countries, Journal of Socio-Economics, Vol.35, 83-101, 2006.

[10] K. Teilmann. Measuring social capital accumulation in rural development, Journal of Rural Studies, Vol. 28, No.4, 458-465, 2012.

[11] L. G. Pochebut and L. V. Mararitsa. Individual Strategies of Managing Social Capital: A New Look at the Psychology of Interpersonal Relationships, Social and Behavioral Sciences, Vol.86, 557-562, 2013.

[12] N. V. Ha, S. Kant and V. W. Maclaren. Relative shadow prices of social capital: An input distance function approach, Ecological Economics, Vol. 57,520-533, 2006.

[13] M. Jaime and C. Salazar. Participation in organizations, technical efficiency and territorial differences: A study of small wheat farmers in Chile, Chilean Journal of Agricultural Research, Vol. 71,104-113, 2011.

[14] O. Waheed and O. Ayodele. Sources of technical efficiency among smallholder maize farmers in Osun state of Nigeria, Research Journal of Applied Science, Vol. 5, 115-122, 2010.

[15] T. Serra and E. Poli. Shadow prices of social capital in rural India, a nonparametric approach, European Journal of Operational Research, Vol.240, No.3, 892-903, 2015.

[16] J. S. Coleman. Social Capital in the Creation of Human Capital, American Journal of Sociology, Vol. 94, No. Supplement, S95-S120, 1988.

[17] J. S. Coleman. Foundations of Social Theory, Harvard University Press, Cambridge, MA, 1990.

[18] M. Taylor. Community, Anarchy and Liberty, Cambridge University Press, Cambridge, UK, 1982.

[19] M. Latham. The Search for Social Capital, Paper presented at There Is Such a Thing as Society seminar, Centre for Independent Studies, Sydney, 1997.

[20] F. Fukuyama. Trust: The Social Virtues and the Creation of Prosperity, New York Free Press, New York, 1995.

[21] L. J. Robison, A. A. Schmid and M. E. Siles. Is Social Capital Really Capital, Review of Social Economy, Vol. LX, 1-21, 2002.

[22] L. J. Robison and L. J. Flora. The Social Capital Paradigm: Bridging across Disciplines, American Journal of Agricultural Economics, Vol. 85, 1187-93, 2003.

[23] K. Lux. The Failure of the Profit Motive, Ecological Economics, Vol. 44, 1-9, 2003.

[24] F. Herreros. The Problem of Forming Social Capital, Why Trust, Palgrave Macmillan, New York, 2004.

[25] R. H. Frank. What Price the Moral High Ground, Ethical 
Dilemmas in Competitive Environments, Princeton University Press, Princeton, NJ, 2004.

[26] S. Bowles and H. Gintis. Social Capital and Community Governance, Economic Journal, Vol.112, No.9, F419-F436, 2002.

[27] R. D. Putnam. Bowling Alone: The Collapse and Revival of American Community, Simon and Schuster, New York, 2000.

[28] J. Beckert. Economic Sociology and Embeddedness, How Shall We Conceptualize Economic Action, Journal of Economic Issues, Vol. XXXVII, No.3, 769-786, 2003.

[29] J. Beckert. Interpenetration versus Embeddedness, American Journal of Economics and Sociology, Vol. 65, No.1, 163-188, 2006.

[30] D. McCloskey. The Bourgeois Virtues: Ethics for an Age of Commerce, University of Chicago Press, Chicago, 2006.

[31] R. C. Solomon. True to Our Feelings: What Our Emotions Are Really Telling Us, Oxford University Press, New York, 2007.

[32] G. A. Cory. A Behavioral Model of the Dual Motive Approach to Behavioral Economics and Social Exchange, Journal of Socio-Economics, Vol. 35, 592-612, 2006.

[33] D. S. Levine. Neural Modeling of the Dual Motive Theory of
Economics, Journal of Socio-Economics, Vol. 35, No.4, 613-625, 2006.

[34] D. R. Wilson. The Evolutionary Neuroscience of Human Reciprocal Sociality: A Basic Outline for Economists, Journal of Socio-Economics, Vol. 35, No.4, 626-633, 2006.

[35] G. D. Lynne. Toward a Dual Motive Meta economic Theory, Journal of Socio-Economics, Vol. 35, 634-651, 2006.

[36] D. Sally. A General Theory of Sympathy, Mind-Reading, and Social Interaction with an Application to the Prisoner's Dilemma, Social Science Information,Vol.39,567-634, 2000.

[37] J. J. Heckman. Sample Selection Bias as a Specification Error, Econometrica, Vol. 47,153-162, 1979.

[38] A. D. Lester. Theories of Personality: A Systems Approach, Taylor and Francis, Washington, D.C., 1995.

[39] J. E. Phares and N. Erskine. The Measurement of Selfish, Educational and Psychological Measurement, Vol.44, 597-608, 1984.

[40] A. Angyal. Foundations for a Science of Personality: The Common Wealth Fund, Harvard University Press, Cambridge, MA, 1941/1967.

[41] D. Sally, I, Too, Sail Past: Odysseus and the Logic of Self-Control, Kyklos, Vol. 53, No.2, 173-200, 2000. 